\title{
Let the Right One In: A Microeconomic Approach to Partner Choice in Mutualisms
}

\section{Citation}

Archetti, Marco, Francisco Úbeda, Drew Fudenberg, Jerry R. Green, Naomi Ellen Pierce, and Douglas W. Yu. 2011. Let the right one in: A microeconomic approach to partner choice in mutualisms. The American Naturalist 177(1): 75-85.

\section{Published Version}

doi:10.1086/657622

\section{Permanent link}

http://nrs.harvard.edu/urn-3:HUL.InstRepos:9962009

\section{Terms of Use}

This article was downloaded from Harvard University's DASH repository, and is made available under the terms and conditions applicable to Other Posted Material, as set forth at http:// nrs.harvard.edu/urn-3:HUL.InstRepos:dash.current.terms-of-use\#LAA

\section{Share Your Story}

The Harvard community has made this article openly available.

Please share how this access benefits you. Submit a story.

Accessibility 


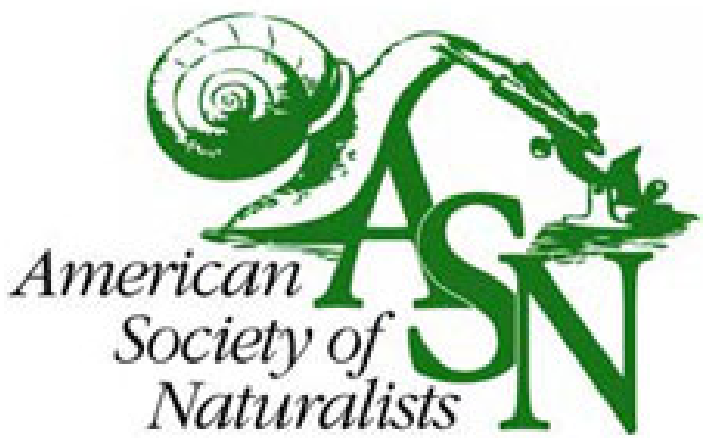

Let the Right One In: A Microeconomic Approach to Partner Choice in Mutualisms. Author(s): Marco Archetti, Francisco Úbeda, Drew Fudenberg, Jerry Green, Naomi E. Pierce, and Douglas W. Yu

Reviewed work(s):

Source: The American Naturalist, Vol. 177, No. 1 (January 2011), pp. 75-85

Published by: The University of Chicago Press for The American Society of Naturalists

Stable URL: http://www.jstor.org/stable/10.1086/657622

Accessed: 30/05/2012 13:14

Your use of the JSTOR archive indicates your acceptance of the Terms \& Conditions of Use, available at http://www.jstor.org/page/info/about/policies/terms.jsp

JSTOR is a not-for-profit service that helps scholars, researchers, and students discover, use, and build upon a wide range of content in a trusted digital archive. We use information technology and tools to increase productivity and facilitate new forms of scholarship. For more information about JSTOR, please contact support@ jstor.org. 


\title{
Let the Right One In: A Microeconomic Approach to Partner Choice in Mutualisms
}

\author{
Marco Archetti, ${ }^{1,2}$ Francisco Úbeda, ${ }^{3}$ Drew Fudenberg, ${ }^{2}$ Jerry Green, ${ }^{2}$ Naomi E. Pierce, ${ }^{1}$ and \\ Douglas W. $\mathrm{Yu}^{4, *}$
}

1. Department of Organismic and Evolutionary Biology, Harvard University, Cambridge, Massachusetts 02138; 2. Department of Economics, Harvard University, Cambridge, Massachusetts 02138; 3. Department of Ecology and Evolutionary Biology, University of Tennessee, Knoxville, Tennessee 37996; 4. Ecology, Conservation, and Environment Center and State Key Laboratory of Genetic Resources and Evolution, Kunming Institute of Zoology, Chinese Academy of Science, Kunming, Yunnan, 650223 China; and School of Biological Sciences, University of East Anglia, Norwich, Norfolk NR4 7TJ, United Kingdom

Submitted April 29, 2010; Accepted October 2, 2010; Electronically published November 22, 2010

ABstract: One of the main problems impeding the evolution of cooperation is partner choice. When information is asymmetric (the quality of a potential partner is known only to himself), it may seem that partner choice is not possible without signaling. Many mutualisms, however, exist without signaling, and the mechanisms by which hosts might select the right partners are unclear. Here we propose a general mechanism of partner choice, "screening," that is similar to the economic theory of mechanism design. Imposing the appropriate costs and rewards may induce the informed individuals to screen themselves according to their types and therefore allow a noninformed individual to establish associations with the correct partners in the absence of signaling. Several types of biological symbioses are good candidates for screening, including bobtail squid, ant-plants, gut microbiomes, and many animal and plant species that produce reactive oxygen species. We describe a series of diagnostic tests for screening. Screening games can apply to the cases where byproducts, partner fidelity feedback, or host sanctions do not apply, therefore explaining the evolution of mutualism in systems where it is impossible for potential symbionts to signal their cooperativeness beforehand and where the host does not punish symbiont misbehavior.

Keywords: cooperation, symbiosis, microbiome, Vibrio fischeri, virulence, parasitism.

\section{Introduction}

\section{The Problem of Partner Choice}

Every mutualism in nature is beset by two fundamental challenges that arise because information is asymmetrically distributed: the host knows less about its potential partner than that partner knows about itself. After an interaction is established, this asymmetry takes the form of hidden

* Corresponding author; e-mail: dougwyu@gmail.com.

Am. Nat. 2011. Vol. 177, pp. 75-85. (C) 2010 by The University of Chicago. 0003-0147/2011/17701-52125\$15.00. All rights reserved.

DOI: $10.1086 / 657622$ actions: what prevents an individual from exploiting the resources of the host or from refusing to cooperate? This problem has been analyzed extensively, and in general, the solution is believed to rely on some form of host-mediated feedback in which symbiont behaviors are rewarded or punished in ways that favor the fitnesses of cooperative symbionts (West et al. 2002a, 2002b; Sachs et al. 2004; Edwards et al. 2006). If the host response evolved de novo as an adaptation to maintain mutualism, then the feedback is termed a host sanction (West et al. 2002a, 2002b), whereas if the host response is a preadapted and generalpurpose response to environmental setbacks, then it is termed a partner fidelity feedback (Weyl et al. 2010).

Before the interaction is established, however, hosts face another fundamental challenge: that of choosing a good partner. Here the information asymmetry takes the form of hidden characteristics: the potential partners know their own quality and can therefore behave accordingly, but the potential host does not. In biology, this is usually known as the problem of "partner choice," and it has been defined to mean interactions in which individuals "differentially reward cooperative vs. uncooperative partners in advance of any possible exploitation" (Bull and Rice 1991, p. 63, italics added). Partner choice is our focus here.

In some situations, the problem of partner choice can be solved by signaling: the informed player sends a costly signal regarding his own quality to the noninformed player, who can accept or reject. Signaling theory is well known in the field of sexual selection and mate choice (Grafen 1990; reviews in Maynard Smith and Harper 2003; Searcy and Nowicki 2005). In addition, although rarely included in the standard repertoire of solutions for the maintenance of mutualism (Yu 2001; Sachs et al. 2004), there do exist a few reports of costly, honest signaling in pollination mutualisms (Møller 1995; Armbruster et al. 2005; see also Schaefer et al. 2004; Edwards et al. 2007). 
However, we will not focus on signaling. Instead, we are interested in the problem of partner choice where signaling is not possible or where the noninformed individual cannot actively choose. Is partner choice possible without signaling?

\section{Partner Choice without Signaling}

Partner choice without signaling occurs in a very wellstudied symbiosis: that between the bioluminescent bacterium Vibrio fischeri and the marine bobtail squid Euprymna scolopes (reviews in Ruby and McFall-Ngai 1999; Small and McFall-Ngai 1999; Visick and McFall-Ngai 2000; Nyholm and McFall-Ngai 2004; Ruby et al. 2004; McFall-Ngai 2008). The squid provides V. fischeri colonies with food and housing inside a specialized light organ, and the bacteria expend energy to produce light, which is taken to benefit the squid (possibly allowing the squid to avoid throwing a moonlight shadow on seafloors, which would reveal its location to predators). Only bioluminescent $V$. fischeri strains have been found in the light organs of the squid, although nonluminescent mutants arise spontaneously in laboratory culture. This is striking if we consider that luminescence per se is not essential for the bacteria; indeed, it demands about $20 \%$ of the metabolic potential of a bacterium, and nonluminescent mutants enjoy higher growth rates under laboratory conditions. However, experimentation reveals that mutant bacteria unable to induce normal luminescence have a three- to fourfold defect in the ability to colonize the squid (Visick et al. 2000). The squid is colonized (mostly) once, at the beginning of its life, and there is no indication that $V$. fischeri is able to honestly signal its luminescence capability before colonization or that the squid is able to identify and punish preferentially nonluminescent strains, although squid macrophages do appear to be able to recognize $V$. fischeri generally (Nyholm et al. 2009). How does a bobtail squid recruit luminescent bacteria when the bacteria cannot signal and the squid cannot choose? We use the $V$. fischeriE. scolopes mutualism to introduce the concept of screening, and we discuss further examples in a later section.

\section{Screening}

An effective method for screening luminescent bacteria from nonluminescent ones would be to impose a strategic cost on the bacteria (a cost that is not necessarily useful otherwise to either party) that induces them to enter the squid only if they are luminescent. The squid seems to have found such a strategy. The light organ of the squid is rich in enzymes that can produce reactive oxygen species (ROSs; e.g., hydrogen peroxide) that are toxic for bacteria, including $V$. fischeri. Only bacteria that produce the en- zyme luciferase are able to prevent damage by ROSs, because luciferase consumes molecular oxygen $\left(\mathrm{O}_{2}\right)$ from the surrounding environment in a reaction that emits light (Ruby and McFall-Ngai 1999). Vibrio fischeri bacteria are selected to pay the cost of luciferase activity because the consequent reduction in oxygen in the light organ removes the input to host production of ROSs. High-quality bacteria (with active luciferase) are able to pay this cost, and in return they receive high levels of food resources (Visick et al. 2000). Low-quality bacteria (without luciferase) find that paying the cost is not profitable (they are not viable in a light organ, due to ROS build-up) and therefore they should not evolve to enter the host.

The equilibrium outcome is that the bacteria self-screen: high-quality bacteria evolve to associate with the host and low-quality bacteria evolve to be free living. Screening by using the threat of ROSs is effective because the quality that is relevant for the squid (light production) is strictly linked (it is a by-product in the same biochemical reaction) with the quality that is relevant for the bacterium to enter the association (prevention of ROS production). Importantly, there is no other known use by the squid for the production of ROSs or the enzymes that produce them, nor is there another known use by this bacteria for luciferase production. Enzyme production appears to be a "strategic waste" of resources, and one that makes screening possible.

In the $V$. fischeri-E. scolopes mutualism, therefore, the problem of partner choice is solved not by signaling (the informed party signals and the noninformed party chooses) but by what we call "screening" (the noninformed party sets up certain conditions that the informed party can accept or reject). This is reminiscent of contract theory in microeconomics.

\section{Model \\ A Microeconomic Approach to Partner Choice}

The problem of hidden characteristics in partner choice exists in microeconomics, too (Bolton and Dewatripont 2005). Imagine an employer facing the problem of hiring an employee. The employee knows his own quality better than the employer does. How does an employer hire only high-quality employees? This problem, in its strategic structure, is not different from the one faced by a host that is trying to establish a mutualistic interaction with a symbiont. In economics, the hidden-characteristics problem is known as the problem of "adverse selection" (Akerlof 1970). The signaling solution to the adverse selection problem was formalized in economics 20 years earlier than in biology (notably, by Spence 1973; reviewed in Hammerstein and Hagen 2005). The screening solution (Roth- 
schild and Stiglitz 1976; Stiglitz 1977) appears to have never been introduced formally to biology, so we do that here.

\section{Two Screening Games}

The simplest version of the problem of adverse selection can be described, using the terminology of economics, as follows: an individual (the principal) wants to contract another (the agent) to engage in an interaction. Agents are of two types $(i=q, Q)$, which the principal cannot tell apart before any association is established; $Q$ agents are mutualistic and $q$ agents are parasitic. Agents cannot signal their type (or, equivalently, the principal cannot choose them). Is it possible for the principal to enter an interaction with $Q$ agents only and to avoid $q$ agents? Or, alternatively, is it possible for the principal to give different rewards to the different types without being able to assess their quality? It is one of the most remarkable results of microeconomics that a solution to this problem exists. In signaling models, the problem of asymmetric information is solved by the fact that the agents signal their quality and then the principal chooses according to that signal. In screening models, by contrast, principals move first by setting up certain demands, and then the agents move second by assessing the demands and choosing whether to accept.

To demonstrate a simple screening game (fig. 1), let us first assume that the principal wants to recruit only $Q$ agents because, say, hosting $q$ agents is worse than hosting no one. To do this, she imposes a cost for entering the interaction, and the cost is designed such that $Q$ agents can afford to pay it and still find it profitable to enter the interaction but $q$ agents cannot afford to pay it and therefore find it profitable to avoid entering the interaction. We call a principal that imposes such a cost a "demanding" principal. In this way, only $Q$ agents will enter the interaction (fig. 1). The agents, in other words, screen themselves in or out according to their own quality; the principal does not choose, and never knows, the quality of any individual agent; she simply sets certain working conditions (a "contract") that the agents, considering the rewards and conditions offered by the principal, evolve to accept (becoming symbionts) or reject (remaining free living).

In the second instance, now let us assume that the principal wants to attract both types of agents; this might occur if hosting a $q$ agent is better than hosting no one. The key to doing so is that multiple different sets of conditions to enter the interaction must be created and tailored to the types of agents that the principal wants to attract. If the contracts (the rewards and the costs) are designed in the right way, the agents will again screen themselves according
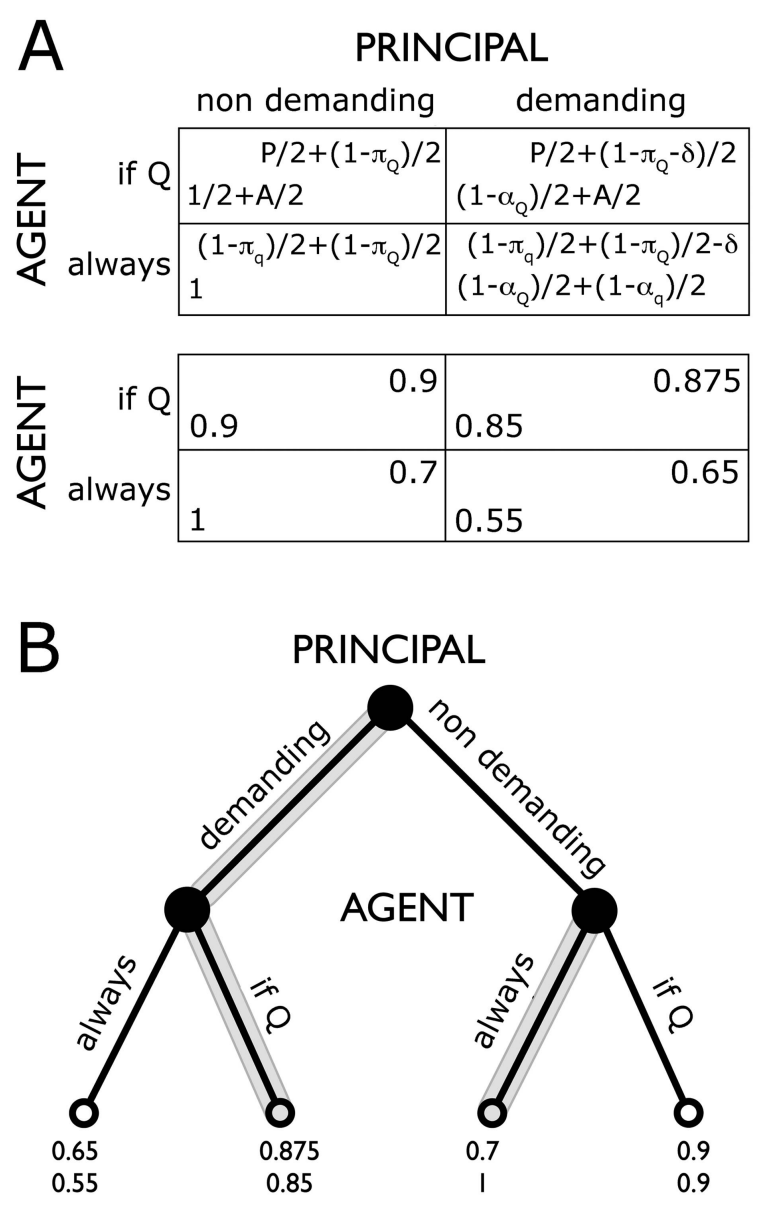

Figure 1: Screening game. The principal can be demanding or nondemanding; the agent can always enter the interaction or enter when he is $Q$ (high quality). The payoff for an agent is 1 when the principal is nondemanding and $1-\alpha_{i}$ when the principal is demanding, where $\alpha_{i}$ is the cost for entering the interaction for an agent of type $i=q, Q(0<$ $\alpha_{\mathrm{Q}}<\alpha_{\mathrm{q}}$ ). The payoff for a principal interacting with an agent of type $i$ is $1-\pi_{i}\left(\pi_{\mathrm{Q}}<\pi_{\mathrm{q}}\right)$; being demanding has a cost $\delta$ for the principal. If the agent does not enter the interaction, he has a payoff $A$; if the principal does not enter the interaction, she has a payoff $P$. The frequency of $Q$ agents is $1 / 2$. A, The game in strategic form. Each cell shows the payoffs to the agent (bottom left) and the principal (top right) in the general case and where $A=0.8, P=0.8, \pi_{\mathrm{Q}}=0, \pi_{\mathrm{q}}=0.6, \alpha_{\mathrm{Q}}=0.1$, and $\alpha_{\mathrm{q}}=$ $0.8 ; \delta=0.05$. In the simultaneous game, the best strategy is for the principal to be nondemanding and for the agent to always enter. $B$, The game in extensive form. The black circles show a player's move; the open circles show the end of a subgame, when payoffs are assigned to the principal (top) and the agent (bottom); gray branches show the dominant strategies for each subgame; the best strategy for the principal is to be demanding and for the agent to enter only when he is $Q$.

to their own quality and the different sets of conditions offered by the principal; the principal will again achieve separation of the two agent types without having to observe and choose. This second instance requires a more 
involved exposition, one possible scenario of which we outline here and in figure 2.

Let there be two types of agents: $\operatorname{good}(i=Q)$ and bad $(i=q)$. Let $w$ be the quantity/quality of rewards provided by the principal and let $e$ be the effort from the agent demanded by the principal (a cost for the agent, a benefit for the principal); the pair $(w, e)$ is known as a contract. Let $\theta_{i}$ be the valuation of food rewards made by a type $i$ agent, where $\theta_{\mathrm{Q}}>\theta_{\mathrm{q}}>0$, and let $c(w)$ be the cost to the principal of producing reward $w$ (an increasing function of $w$ ). The fitness function of an agent of quality $i$ is

$$
a_{i}(w, e)=\theta_{i} w-e,
$$

and the fitness function of the principal is

$$
p(w, e)=e-c(w)
$$

Both agent and principal try to maximize their own fitness functions.
If a principal is unable to choose the identity of its agents but can nonetheless discriminate between the two types once colonized, a principal interacting with good agents would simply demand high effort and offer high rewards $\left(w_{\mathrm{Q}}, e_{\mathrm{Q}}\right)$ and would derive a high fitness $p=h+\epsilon$, where $\epsilon$ is an increment of fitness gained by hosting a good agent and $p=h$ is the fitness gained by hosting a bad agent. A principal interacting with a bad agent would have no choice but to demand less effort (a bad agent by its nature cannot provide more) and also offer low rewards $\left(w_{\mathrm{q}}, e_{\mathrm{q}}\right)$. As a result, the second principal would derive a lower fitness, $p=h$, but one that is the best achievable (fig. $2 A$ ). In short, $w_{\mathrm{Q}}>w_{\mathrm{q}}$ and $e_{\mathrm{Q}}>e_{\mathrm{q}}$. Furthermore, assuming that all agents are specialists, each type of agent would "sign" its contract (evolve to accept the interaction) as long as the value of the contract were even slightly positive, $a_{i}(w, e)>0$.

However, if principals were unable to direct the appropriate contract to each agent type, a process known in
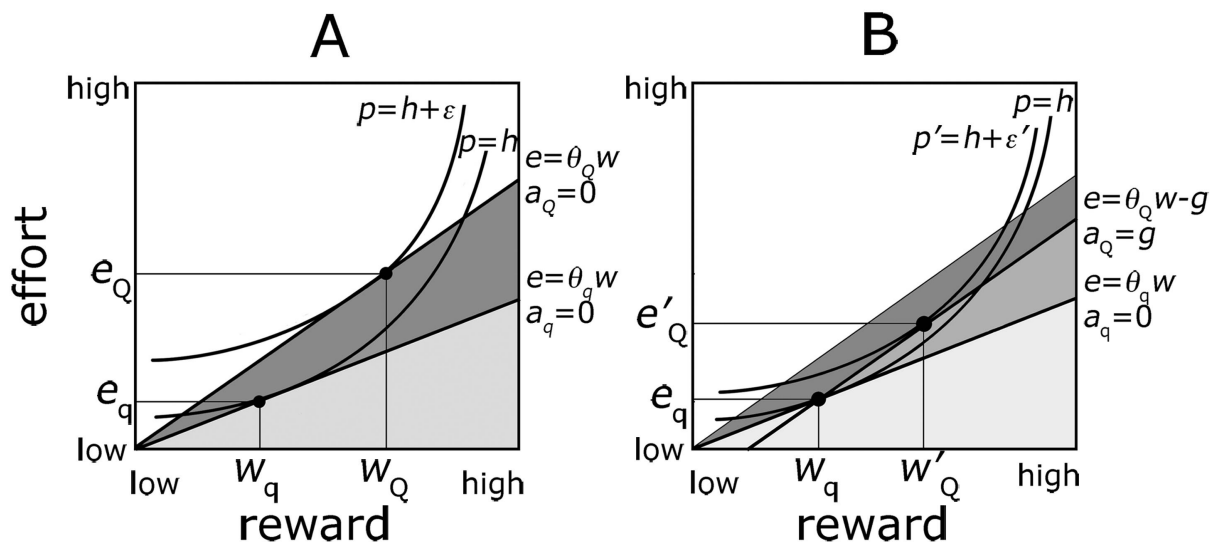

Figure 2: Adverse selection and market segmentation. The graphs represent the set of all possible reward-for-protection contracts ( $w$, $e$ ) between agents and principals. Curves to the upper left indicate increments in fitness ( $p$ ) for the principal (less reward, more effort), and lines to the lower right indicate increments in fitness $(a)$ for the agents (more reward, less effort). For each agent type there is a set of points, which we call the "contract boundary," defined here by the lines $e=\theta_{i} w$; the boundaries represent contracts for which $a_{i}=0$, and all contracts below the boundary confer positive fitness to the agent. By definition, good agents derive higher fitness from a fixed quantity of reward (value the reward more) than do bad agents, so $\theta_{\mathrm{Q}}>\theta_{\mathrm{q}}$. As a result, principals can feasibly demand from good agents more effort $e$ for the same amount of reward $w$ than from bad agents, and thus, good agents have a larger contract space in which fitness is positive. Principals maximize their fitness $p$ by offering contracts at the boundary (i.e., demanding the most effort for a given amount of reward); they derive a greater fitness from good agents $(p=h+\epsilon)$ than from bad agents $(p=h)$. A, If principals can discriminate between good and bad agents after colonization, then when they are hosting good agents, $p$ would be maximized with a high-effort contract $\left(w_{\mathrm{Q}}, e_{\mathrm{Q}}\right)$, and when they are hosting bad agents, it would be maximized with a low-effort contract $\left(w_{\mathrm{q}}, e_{\mathrm{q}}\right.$; curved lines). However, if principals cannot limit each agent type to the appropriate contract, adverse selection occurs and good agents are selected to choose the $\left(w_{\mathrm{q}}, e_{\mathrm{q}}\right)$ contract, which lies below the contract boundary for the good agent and thus confers greater fitness to the good agent than does the boundary $\left(w_{\mathrm{Q}}, e_{\mathrm{Q}}\right)$ contract, specifically $a_{\mathrm{Q}}=g>0$. In short, good agents evolve to be lazy because the opportunity is there to do so. $B$, If principals cannot discriminate, market segmentation (screening) can nonetheless be made to occur; a mutant principal evolves to offer a new contract at $\left(w_{\mathrm{Q}}^{\prime}, e_{\mathrm{Q}}^{\prime}\right)$ along the new boundary $e=\theta_{\mathrm{Q}} w-g$, which lies within the region of positive fitness for the good agent, $a_{\mathrm{Q}}=g>0$. Compared with the original, the new boundary means that the mutant principal demands lower effort for any given amount of reward, which can be interpreted as the transfer of fitness from the principal to the agent; the value of that transfer should evolve to be no more than needed to make the $\left(w_{\mathrm{Q}}^{\prime}, e_{\mathrm{Q}}^{\prime}\right)$ and $\left(w_{\mathrm{q}}, e_{\mathrm{q}}\right)$ contracts equivalent in the eyes of the good agent so that the good agent is indifferent between the two contracts and evolves to colonize both types of principal. In contrast, the bad agent continues to colonize only $\left(w_{\mathrm{q}}, e_{\mathrm{q}}\right)$ principals, because $\left(w_{\mathrm{Q}}^{\prime}\right.$, $\left.e_{\mathrm{Q}}^{\prime}\right)$ would provide a negative fitness. The new mutant principal consequently enjoys higher fitness, $p^{\prime}=h+\epsilon^{\prime}>h$. 
economics as adverse selection would take place. The bad agent has no incentive to "break" its contract, but the good agent does because the good agent's fitness is higher under the less demanding $\left(w_{\mathrm{q}}, e_{\mathrm{q}}\right)$ contract, since the good agent can gain more fitness with lower effort $\left(\theta_{\mathrm{Q}} w_{\mathrm{q}}-e_{\mathrm{q}}>\right.$ $\theta_{\mathrm{Q}} w_{\mathrm{Q}}-e_{\mathrm{Q}}$ ) than it loses with lower rewards (fig. $2 B$ ). As a result, both types of agents would sign the minimumprotection contract $\left(w_{\mathrm{q}}, e_{\mathrm{q}}\right)$, and the principal would lose fitness (from $p_{\mathrm{Q}}=h+\epsilon$ to $p_{\mathrm{q}}=h$ ) and evolve to offer only low-protection contracts. In biological terms, under the conditions presented here, the presence of unobservable parasites in the system causes good agents to be selected to be more parasitic, even though it would be to their hosts' and their own benefit to exchange more resources for more protection.

Hence, there is a selective advantage for the principal to evolve a new contract $\left(w_{\mathrm{Q}}^{\prime}, e_{\mathrm{Q}}^{\prime}\right)$ that offers an intermediate level of rewards in exchange for an intermediate level of effort, that is, $w_{\mathrm{Q}}>w_{\mathrm{Q}}^{\prime}>w_{\mathrm{q}}$ and $e_{\mathrm{Q}}>e_{\mathrm{Q}}^{\prime}>e_{\mathrm{q}}$. Importantly, the new contract $\left(w_{\mathrm{Q}}^{\prime}, e_{\mathrm{Q}}^{\prime}\right)$ would evolve to values such that good agents get the same fitness that they get from the low protection contract $\left(w_{\mathrm{q}}, e_{\mathrm{q}}\right)$. That is, the new contract lies on the same agent fitness isocline as the $\left(w_{\mathrm{q}}\right.$, $e_{\mathrm{q}}$ ) contract where $a_{\mathrm{Q}}=g>0$. When the principal offers a small improvement of the contract, good agents are no longer indifferent and they sign for this intermediate contract. The interesting consequence of this new intermediate contract is that it causes market segmentation by persuading each type of agent to reveal its preference. Bad agents continue to sign up only for principals offering the original contract $\left(w_{\mathrm{q}}, e_{\mathrm{q}}\right)$, but good agents are indifferent between contracts $\left(w_{\mathrm{q}}, e_{\mathrm{q}}\right)$ and $\left(w_{\mathrm{Q}}^{\prime}, e_{\mathrm{Q}}^{\prime}\right)$. Therefore, principals offering the low-protection contract $\left(w_{\mathrm{q}}, e_{\mathrm{q}}\right)$ are colonized by good and bad agents, but principals offering the alternative contract $\left(w_{\mathrm{Q}}^{\prime}, e_{\mathrm{Q}}^{\prime}\right)$ are colonized only by good agents (fig. $2 B$ ). The principal derives an intermediate fitness from hosting good agents $p^{\prime}=h+\epsilon^{\prime}$, where $\epsilon>$ $\epsilon^{\prime}>0$.

\section{Finding the Optimal Contract}

The simple game (fig. 1) and the more involved analysis (fig. 2) discussed above suggest how choosing the right costs and rewards can allow a principal to screen agents of unknown quality, but both analyses are useful only at a conceptual level. One wants to ask whether the costs and rewards are the optimal values. In other words, how do we calculate the optimal contract? The method of constrained optimization, which we introduce here, provides a way to find the optimal effort to impose and the optimal reward to offer (for a more general treatment on constrained maximization, see, e.g., Simon and Blume 1994; Bolton and Dewatripont 2005). We also describe, in a later section, how the model can be mapped to the specific case of the Vibrio fischeri-Euprymna scolopes mutualism.

We assume that the principal can offer a reward $w$ to an agent for a task that requires an effort $e$. The fitness of the agent depends on the benefit $u(w)$ he gets from the reward $w$ and from the cost $v(e)$ of the effort $e$; that is, $u(w)-v(e)$. Benefit and cost are increasing in $w$ and $e$, respectively. If an agent does not interact with a principal, he gets a payoff for free living that is called the agent's reservation utility $(A)$. An agent will find it profitable to accept interacting with a principal if and only if his net utility from entering the interaction is at least as large as $A$. The fitness of the principal depends on the benefit $b(e)$ he gets from the effort $e$ and on the cost $c(w)$ of the reward $w$. Benefit and cost are increasing in $e$ and $w$, respectively. If a principal does not interact with an agent, he gets a payoff $P$ (the principal's reservation utility). The problem for the principal is to set up the right conditions $\left(w^{*}\right.$ and $\left.e^{*}\right)$ to maximize her own fitness, subject to the constraint that only $Q$ agents accept the interaction (e.g., the scenario in fig. 1). That is,

$$
\operatorname{Max}_{(e, w)}(b(e)-c(w))
$$

subject to

$$
\begin{gathered}
u(w)-v(e) \geq A, \\
u(w)-k v(e)<A,
\end{gathered}
$$

where $k>1$ specifies that a $q$ agent has a larger disutility than a $Q$ agent for the same effort level.

Alternatively, we can assume that the principal can offer two different tasks, one designed for low-quality agents $(i=q)$ and one for high-quality agents $(i=Q$; e.g., the scenario in fig. 2). In this case, the benefit and the cost for the agents $\left(u\left(w_{i}\right)\right.$ and $\left.v\left(e_{i}\right)\right)$ and for the principal $\left(b\left(w_{i}\right)\right.$ and $\left.c\left(e_{i}\right)\right)$ depend on the effort $e_{i}$ and reward $w_{i}$ associated with the task chosen by each agent. If $f_{i}$ is the frequency of agents of type $i$, then the fitness of the principal is $f_{\mathrm{Q}}\left(b\left(e_{\mathrm{Q}}\right)-c\left(w_{\mathrm{Q}}\right)\right)+f_{\mathrm{q}}\left(b\left(e_{\mathrm{q}}\right)-c\left(w_{\mathrm{q}}\right)\right)$. The problem for the principal is to maximize her own fitness, subject to two kinds of constraints. First, both types of agents must find the conditions of the interaction more profitable than being free living (constraints [2b] and [2c]); second, each agent type must prefer the conditions designed for that type to the ones designed for the other type (constraints $[2 \mathrm{~d}]$ and $[2 \mathrm{e}])$ :

$$
\operatorname{Max}_{\left(e_{\mathrm{q}}, w_{\mathrm{q}}, e_{\mathrm{Q}}, w_{\mathrm{Q}}\right)} f_{\mathrm{Q}}\left(b\left(e_{\mathrm{Q}}\right)-c\left(w_{\mathrm{Q}}\right)\right)+\left(1-f_{\mathrm{Q}}\right)\left(b\left(e_{\mathrm{q}}\right)-c\left(w_{\mathrm{q}}\right)\right)
$$

subject to 


$$
\begin{aligned}
& u\left(w_{\mathrm{Q}}\right)-v\left(e_{\mathrm{Q}}\right) \geq A, \\
& u\left(w_{\mathrm{q}}\right)-k v\left(e_{\mathrm{q}}\right) \geq A, \\
& u\left(w_{\mathrm{Q}}\right)-v\left(e_{\mathrm{Q}}\right) \geq u\left(w_{\mathrm{q}}\right)-v\left(e_{\mathrm{q}}\right), \\
& u\left(w_{\mathrm{q}}\right)-k v\left(e_{\mathrm{q}}\right) \geq u\left(w_{\mathrm{Q}}\right)-k v\left(e_{\mathrm{Q}}\right) .
\end{aligned}
$$

The solution is that the task designed for $q$ agents must be less demanding than the task designed for $Q$ agents, and it must also be sufficiently less rewarding that $Q$ agents do not choose it.

\section{A Numerical Example}

Consider the following example. Let the cost of the reward $c(w)=w$ and the benefit of the effort $b(e)=\beta e$ for the principal be linear functions of $w$ and $e$, respectively $(\beta>0)$. Let the benefit of the reward $u(w)=w$ for the agent also be linear in $w$, while the cost $v(e)=e^{2}$ of the effort be nonlinear in $e$.

If the principal offers only one task (designed for the $Q$ agents), the solution is given by equation (1a) subject to conditions (1b) and (1c): the optimal effort required is $e^{*}=\beta / 2$ and the optimal reward is $w^{*}=A+e^{* 2}$; therefore, the reward paid at equilibrium increases with $A$ and $\beta$ (the reward paid to the agents must be higher if their reservation utility $A$ and the effort required are high). At equilibrium, $Q$ agents have fitness $w^{*}-e^{* 2}=A$ if they interact with a principal. That is, at equilibrium, agents are indifferent to being free living or entering the symbiosis; an infinitesimal additional reward $\epsilon$ is sufficient to induce agents to enter the interaction. In contrast, $q$ agents, if they accepted the interaction, would have fitness $w^{*}-k e^{* 2}<A$; therefore, $q$ agents do not accept. The principal has fitness $f_{\mathrm{Q}}\left(\beta e^{*}-w^{*}\right)+\left(1-f_{\mathrm{Q}}\right) P$ if the total number of available partners ( $q$ and $Q$ ) is the same as the number of required partners, or it has fitness $\left(\beta e^{*}-w^{*}\right)$ if there are enough $Q$ agents to partner all principals.

If the principal offers two tasks, the solution is given by equation (2a) subject to conditions (2b)-(2e): the optimal effort required for task 1 is still $e_{1}^{*}=\beta / 2$, which will attract only $Q$ agents, but the reward for this task is now increased to $w_{1}^{*}=A+e_{1}^{* 2}+(k-1) e_{2}^{* 2}$. The portion in excess of $A+e_{1}^{* 2}$ (the optimal reward in the case of one task) is needed in order to dissuade $Q$ agents from choosing task 2. The effort required in task 2 is $e_{2}^{*}=\beta\left(f_{\mathrm{Q}}-\right.$ $1) /\left[2\left(f_{\mathrm{Q}}-k\right)\right]$, and the reward offered is $w_{2}^{*}=A+k e_{2}^{*}$. Both are lower than for task 1 , but now $q$ agents will find it profitable to accept task 2; $Q$ agents instead will prefer task 1 because of its increased reward $(k-1) e_{2}^{* 2}$. This excess profit is known as the "informational rent" that accrues to the $Q$ agent as the result of the principal's inability to tell agent types apart a priori. $Q$ agents have fitness $w_{1}^{*}-e_{1}^{* 2}=A+(k-1) e_{2}^{* 2}>A$, while $q$ agents have fitness $w_{2}^{*}-k e_{2}^{* 2}=A$. Note that the principal would have had to pay only $A+\epsilon$ if she could differentiate $Q$ from $q$ agents. The informational rent $(k-1) e_{2}^{* 2}$ is the cost to pay with asymmetric information to achieve separation when signaling is not possible. The principal has fitness $f_{\mathrm{Q}}\left(\beta e_{1}^{*}-\right.$ $\left.w_{1}^{*}\right)+\left(1-f_{\mathrm{Q}}\right)\left(\beta e_{2}^{*}-w_{2}^{*}\right)$.

Should the principal offer one or two tasks? Offering only one task (to $Q$ agents) instead of two tasks results in a higher expected payoff to the principal if $P>\beta^{2}(g-$ 1)/[4( $\left.\left.f_{\mathrm{Q}}-k\right)\right]$; that is, the reservation utility $P$ for the principal must be large enough to make offering one task worthwhile (it must be worth it to be free living). This situation could be obtained, for example, if $q$ agents are parasites. If $P$ is not sufficiently high, the principal will prefer to offer contracts to low-quality individuals too, even though this results in the principal paying the informational rent. That said, it will not always be biologically feasible to offer two tasks; the situation in which only one task is offered (and the alternative for the agent is to remain free living) seems easier to envisage in biology.

\section{Discussion}

\section{The Vibrio fischeri-Euprymna scolopes Symbiosis}

At a qualitative level, there are at least four simple predictions that should be tested in order to classify partner choice as screening. We will discuss these predictions for the case of the $V$. fischeri-E. scolopes symbiosis as a suggestion for possible further tests in this system. Analogous considerations can be made for other systems.

1. A strategic cost imposed on the potential symbionts. The detoxification of ROSs requires about $20 \%$ of the metabolic costs of the bacteria; the cost of the production of ROSs by the squid is also nonnegligible.

2. Active screening of the potential symbionts. Did luminescent bacteria evolve to enter squid? Did putative nonluminescent symbionts evolve to avoid entering, or did they never evolve to enter in the first place? Although this aspect of the evolutionary history of the symbiosis is not known, there is strong indirect evidence. Colonization is an active behavior by $V$. fischeri in that they swim up a duct to the light organ against a squid-produced current (Nyholm and McFall-Ngai 2003). A desirable test of active screening would be to observe the evolution of bacteria in environments with squid that do not produce ROSs (or in which ROSs are neutralized in some way); a nondemanding host should lead to the evolution of nonluminescent strains that colonize the squid.

3. Lack of signaling. Signaling does not rule out the possibility of additional screening mechanisms. However, a lack of signaling or the inability of the host to choose 
its partners clearly makes a stronger case for screening. It seems clear that signaling is absent in the V. fischeri-E. scolopes mutualism: the bacteria do not luminesce before colonization, and the squid is unable to choose among them anyway.

4. Lack of punishment. Screening does not rule out the possibility of additional punishment mechanisms to enforce cooperation, and the occurrence of punishment does not rule out screening before the mutualism is established. A lack of punishment, however, would make the need for screening stronger. We could hypothesize that bobtail squid take in all bacteria and kill off the ones that cannot detoxify ROSs. In fact, indiscriminate uptake of bacteria and small particles does occur in the first hour of the squid's life (Nyholm and McFall-Ngai 2003). However, because $V$. fischeri is rare in the environment, indiscriminate uptake of bacteria as a sole strategy would fill the light organ almost entirely with nonmutualistic bacteria; in fact, the light organ empties before colonization by $V$. fischeri. Furthermore, because detoxification of the light organ environment requires wholesale reduction in oxygen concentration, it is not possible to kill off nonluminescent bacteria selectively.

The model also makes quantitative predictions that depend on three parameters and four functions. If one could manipulate these parameters and know the shape of these functions, one could predict the optimal reward and cost and therefore conduct quantitative tests of the screening mechanism. The parameters are as follows:

$\mathrm{P}$, the reservation utility for the squid. Squid lacking the light provided by $V$. fischeri should suffer a fitness cost, probably in the form of higher predation risk; therefore, it is reasonable that symbiosis with the bacteria confers a higher fitness on the squid than the squid would have living without bacteria. This advantage has not yet been quantified.

A, the reservation utility for the bacteria. The benefits of the interaction for the bacteria are difficult to measure in practice. However, a necessary condition that might be possible to measure is that $A$ should be greater than the fitness inside the squid for nonluminescent bacteria but less for luminescent bacteria. This seems reasonable: luminescent $V$. fischeri strains that colonize the squid reach densities in seawater that are orders of magnitude higher than those attained by free-living strains (Lee and Ruby 1994). In contrast, experimental replacement of $V$. fischeri in the light organ by nonluminescent bacteria should result in the death of the latter by ROSs.

$\mathrm{k}$, the ratio of the cost for $\mathrm{q}$ agents to the cost for $\mathrm{Q}$ agents for a given effort level. This ratio is very high in this case, as ROSs are lethal for nonluminescent strains. Because only one task is offered in this case, quantifying $k$ is not important (as long as it is $>1$, which is clearly the case); it could be important in other systems, however, in which $k$ is smaller. A necessary condition, and one that is probably easy to measure, is that $k>1$.

The functions are as follows:

$\mathrm{c}(\mathrm{w})$, the cost (for the squid) as a function of the reward. Unpublished data (E. Ruby, personal communication) show that the squid's body weight (a measure of the cost) decreases with the amount of bacteria hosted in the light organ (a measure of the reward). These data could be used to plot $c(w)$.

$\mathrm{u}(\mathrm{w})$, the benefit (for the bacteria) as a function of the reward. This is simply the amount of bacteria released daily as a function of the bacteria hosted by the squid. The squid releases about $95 \%$ of the $V$. fischeri colony every dawn and regrows it during the day.

$\mathrm{b}(\mathrm{e})$, the benefit (for the squid) as a function of the effort of the bacteria. This is not easy to measure, as it seems that the squid can adjust the amount of light and because the amount of light depends on coordination and quorumsensing among the bacteria. However, as we state above, it appears reasonable, though unquantified, that zero effort by the bacteria confers no benefit on the squid.

$\mathrm{v}(\mathrm{e})$, the cost (for the bacteria) as a function of the effort. It is known that luminescence demands about $20 \%$ of the metabolic costs of the bacteria. The shape of the function could be determined by measuring the metabolic costs at different intensities of light.

What is known about this symbiosis seems consistent with the assumptions that $c(w), u(w), b(e)$, and $v(e)$ are increasing in $w$ and $e$, respectively, and that $P, A$, and $k$ take on values that are consistent with the screening. That said, the functions are difficult to measure in practice, even for a well-characterized symbiosis like $V$. fischeri-E. scolopes.

\section{Other Microbial Symbioses}

High ROS concentrations occur not only within the light organ of the bobtail squid but also in other squid tissues that come into contact with bacteria (Small and McFallNgai 1999; Davidson et al. 2004). Moreover, the enzyme halide peroxidase, which converts hydrogen peroxide into highly toxic hypochlorous acid, is common in the tissues of fish, mollusks, insects, worms, and cnidarians that support cooperative bacterial associations (Ruby and McFallNgai 1999). In addition, the roots of leguminous plants exhibit a massive production of ROSs during the initiation of symbiosis with nitrogen-fixing rhizobial bacteria, and this has been interpreted as a mechanism to control bacterial entry (Heath and Tiffin 2009; Soto et al. 2009; Glyan'ko and Vasil'eva 2010). It would appear counterintuitive to produce compounds that are lethal for bacteria when trying to establish a symbiosis with bacteria, but an 
interesting feature of bacteriophage genetics opens the possibility for screening as a widespread feature of symbioses with bacteria.

Selva et al. (2009) have shown that $\mathrm{H}_{2} \mathrm{O}_{2}$ exposure can induce the lysis of a pathogenic bacterium, Staphylococcus aureus. The $\mathrm{H}_{2} \mathrm{O}_{2}$ does not kill the $S$. aureus directly, but rather it causes low levels of DNA damage that induce the SOS DNA repair mechanism. Many $S$. aureus contain phage DNA; the SOS response activates the phage DNA, which produces offspring viral particles and lyses the bacterial cell, apparently to prevent DNA repair from inadvertently mutating important phage genes. The key point is that inserted phage DNA often contains genes for virulence factors ("pathogenicity islands"; Schmidt and Hensel 2004; Sui et al. 2009), which creates the necessary correlation between pathogenicity and susceptibility to ROSs. In theory, then, host organisms should be able to separate pathogenic from nonpathogenic bacteria by creating an ROS-rich environment. "Low-quality" species (with pathogenicity islands) will be under selection to avoid the cost of entering into association with the host (because of the risk of lysis), while "high-quality" (nonpathogenic) species will not. Note that because the correlation of pathogenicity with the presence of phage DNA is imperfect, so is the ability of hosts to screen.

\section{Ant-Plant Symbioses}

The problem of hidden characteristics occurs regularly in ant-plant symbioses. Many ant-plants associate with multiple ant species that vary in their quality to patrol and protect the plant's leaves (Yu and Davidson 1997; Yu 2001; Heil and McKey 2003; Bruna et al. 2004; Tillberg 2004; Frederickson 2005). The identity of the ant symbiont tends to be determined at the time that ant queens colonize (Yu and Davidson 1997; Yu et al. 2001; Debout et al. 2009).

Screening mechanisms are consistent with two ant-plant symbioses. The ant-tree Cecropia pungara establishes in forest gaps, where it is regularly overtopped due to its intrinsically slow growth, but it can survive at low light, waiting for the next treefall (Folgarait and Davidson 1994). In southern Peru, the most frequent ant symbiont, Pachycondyla luteola (Yu and Davidson 1997), has a low basal activity level and a nitrogen-based sting, making it suitable for low-carbon conditions (Davidson et al. 2003), whereas other, less suitable ant species exhibit high activity levels and carbon-based spray defenses (Davidson et al. 2003). About $90 \%$ of C. pungara individuals are inhabited by Pachycondyla, which in turn establishes only on this species (Yu and Davidson 1997). How is this species specificity achieved? We suggest that $C$. pungara saplings can bias competition in favor of Pachycondyla queens because saplings produce food bodies early in development, some- times even before ant housing occurs (Folgarait and Davidson 1994; Yu and Davidson 1997). Only Pachycondyla queens gather food during colony founding, which is thought to accelerate worker production, thereby improving their ability to outcompete other ant species. Thus, Pachycondyla is both a high-quality and a competitively superior symbiont, both on account of being a ponerine ant.

Another apparent example of partner choice is given by four regionally sympatric species of Mesoamerican ant acacias. Two of the species, Acacia cornigera and Acacia collinsii, provide high levels of food and housing, and $\geq 95 \%$ of the trees in these two species are inhabited by mutualistic Pseudomyrmex ant species. The other two species, Acacia hindsii and Acacia chiapensis, provide much less food and half the housing, and $40 \%-60 \%$ of trees in these two low-reward species are inhabited by parasitic, nonprotecting Pseudomyrmex ant species (Heil et al. 2009). In short, almost all high-reward Acacia trees are inhabited by high-quality ant symbionts, while about half of the lowreward Acacia trees are inhabited by low-quality symbionts. Heil et al. (2009) propose that this pattern of association results from "massive competition for host plants" (p. 18092).

When nonprotecting and protecting Pseudomyrmex ant queens colonize different parts of a high-reward Acacia, the part colonized by the protecting ant species grows more quickly, allowing the protecting ant species to build up a large colony and kill off competitors (Heil et al. 2009; see also Frederickson and Gordon 2009). On low-reward Acacia species, patrolling does not increase achieved leaf area, suggesting higher levels of chemical defenses, a lower feedback value of protecting (Heil et al. 2009), and thus a weakened competitive hierarchy.

In both ant-plant systems, the demanding task is to compete for the host plant, and this competition is costly to the ants because of the risk of losing and because any resources diverted to fighting (or preparing to fight) detract from colony growth. Competition also therefore appears to be a cause of resource waste for the ants. Similarly, for the plant, resources invested in promoting competition (excess housing so that multiple queens can colonize) and in biasing its outcome (early food production) are wasted resources except in the context of screening out lowquality ant species.

\section{Gut Microbiomes}

More speculatively, there appears to be a scope for applying ideas from screening to the development and evolution of symbiotic microbiomes. For instance, the most abundant component of human milk is lactose (Zivkovic et al. 2010); the lac operon repressor, lacI, which is needed for the 
efficient regulation of lactase production, has been shown to reduce virulence in the pathogen Salmonella enterica, although the mechanism remains unclear (Eswarappa et al. 2009). Host environments rich in lactose could confer a competitive advantage on lactose-consuming - and thus lactase-producing-microbes, which would necessarily also be avirulent. Continuing along this speculative line, lactose intolerance in hosts might have a selective advantage in habitats with high pathogen prevalence. Moreover, many of the other oligosaccharides in human milk appear to be directed toward the preferential nutrition of a coevolved, nonpathogenic bacterium associated with human infants, Bifidobacterium longum subsp. infantis, which presumably confers to this species a growth-rate advantage over pathogenic bacteria (Zivkovic et al. 2010). However, for this to qualify as a screening mechanism, we would need to understand why B. longum does not itself evolve pathogenicity; an alternative (although not mutually exclusive) hypothesis is that the oligosaccharides evolved to inhibit the adhesion of pathogens to intestinal cells and B. longum evolved to take advantage of this resource.

\section{A New Look at Partner Choice}

Almost 20 years ago, Bull and Rice's (1991) partner choice model proposed that mutualism would be maintained if hosts could associate only (or mostly) with mutualistic symbionts. However, other than in some reports of costly signaling in pollination mutualisms (Møller 1995; Armbruster et al. 2005), no mechanism for achieving partner choice has been described, prompting some authors to widen the definition of partner choice to include mechanisms that monitor symbiont behavior and reward or punish appropriately (Sachs et al. 2004). We propose instead to differentiate between hidden actions and hidden characteristics, with only the latter being considered problems of partner choice and modeled using signaling and screening games. In this, we follow the tradition of games with asymmetric information in microeconomics, which consider "signaling" and "screening" to be two solutions to the problem of hidden characteristics.

Screening games apply to the difficult cases where the interaction is not a repeated game or vertically transmitted, where it is impossible for potential symbionts to signal their cooperativeness, and where the host cannot punish symbiont misbehavior. Many bacterial and fungal symbioses would appear to fall into this category (e.g., Arnold et al. 2003; Dethlefsen et al. 2007; Gibson and Hunter 2010), which argues that screening could be a common mechanism for achieving mutualism.

Screening is also consistent with the long-standing hypothesis (Thompson 1982; Gibson and Hunter 2010) that mutualisms evolved from parasitism. This is because host- imposed costs seem likely to have evolved from host defenses against parasites. For instance, Ruby and McFallNgai (1999) have speculated that the origin of luciferase lies in the context of parasitism, because an alternative pathway for this enzyme produces oxygen radicals that can be used to attack host tissue. An ancestral V. fischeri using luciferase as a virulence factor would have been preadapted to respond to the evolution of ROS production by a host, with the by-product of light.

Finally, we end with the suggestion that by promoting long-term specificity, screening mechanisms could set the stage for further pairwise coevolution between hosts and mutualistic symbionts. This could allow symbionts and hosts to evolve complex mutual-recognition mechanisms (e.g., Yu and Davidson 1997; Brouat et al. 2001; Mueller et al. 2004; Oldroyd and Downie 2008; Nyholm et al. 2009) and pairwise adaptations in symbionts to induce host rewards (Risch and Rickson 1981; Heil et al. 2009) and tolerate host defenses (e.g., Poulsen et al. 2003).

Screening (and partner choice in general) does not eliminate the problem of hidden actions, that is, the incentive to free ride once the interaction is established. For example, in the case of the $V$. fischeri-E. scolopes symbiosis, the detoxification of ROSs is, to a certain extent, a public good: nonluminescent individuals that managed to establish an interaction could exploit the public good eventually produced by its neighbors, which would lead to a social dilemma (Archetti 2009a, 2009b). Because the host benefits from reducing the number of free riders anyway, this still leaves room for the evolution of a screening strategy by the host. In short, screening, like signaling, eliminates the hidden-characteristics problem, thereby reducing but not eliminating the hidden-actions problem.

It is a little surprising that screening games have not already been introduced to the symbiosis literature, given their prominence in microeconomics. While screening in economics implies rationality of agents and principals trying to maximize their profit, in biology, rationality is replaced by natural selection and the best-response concept of economics is replaced by evolutionary dynamics. In other words, while a trained economist can solve the constrained-optimization problem to find the optimal contract, natural selection replaces rationality in the case of mutualism and leads to "natural contracts" with the optimal costs and rewards. Several types of biological symbioses seem to be good candidates for screening; we have proposed a few and hope to stimulate further research on screening in biology.

\section{Acknowledgments}

We thank D. Ebert, M. Frederickson, M. Hoffman, G. Weyl, and M. Wollenberg for insightful comments. We 
greatly benefited from discussing the squid-bacteria mu $\rightarrow$ tualism with N. Ruby and from reviews by S. Frank, H. Gintis, and an anonymous reviewer. We received funding from National Science Foundation grant SES-075048C awarded to N.E.P., J.G., and D.F. under the aegis of a grant from the European Science Foundation/European Collaborative Research/the Evolution of Cooperation and Trading (ESF/EUROCORES/TECT) to the BIOCONTRAC1 consortium that also included D.W.Y., U. Dieckmann, F. Dionisio, D.F., J.G., J. Orivel, N.E.P., F.Ú., and I. Scheuring, and we also received funding from the Yunnan provincia' government（云南省高端科技人才引进计划 20080A001） and the Chinese Academy of Sciences (0902281081; awarded to D.W.Y.).

\section{Literature Cited}

$\rightarrow$ Akerlof, G. A. 1970. The market for "lemons": quality uncertainty and the market mechanism. Quarterly Journal of Economics 84. 488-500.

$\rightarrow$ Archetti, M. 2009a. Cooperation as a volunteer's dilemma and the strategy of conflict in public goods games. Journal of Evolutionary Biology 22:2192-2200.

$\rightarrow$. 2009b. The volunteer's dilemma and the optimal size of a social group. Journal of Theoretical Biology 261:475-480.

$\rightarrow$ Armbruster, W., L. Antonsen, and C. Pelabon. 2005. Phenotypir selection on Dalechampia blossoms: honest signaling affects pollination success. Ecology 86:3323-3333.

$\rightarrow$ Arnold, A. E., L. C. Mejia, D. Kyllo, E. I. Rojas, Z. Maynard, N. Robbins, and E. A. Herre. 2003. Fungal endophytes limit pathogen damage in a tropical tree. Proceedings of the National Academy of Sciences of the USA 100:15649-15654.

Bolton, P., and M. Dewatripont. 2005. Contract theory. MIT Press. Cambridge, MA.

$\rightarrow$ Brouat, C., N. Garcia, C. Andary, and D. McKey. 2001. Plant lock and ant key: pairwise coevolution of an exclusion filter in an antplant mutualism. Proceedings of the Royal Society B: Biologicaı Sciences 268:2131-2141.

$\rightarrow$ Bruna, E. M., D. M. Lapola, and H. L. Vasconcelos. 2004. Interspecific variation in the defensive responses of obligate plant-ants: experimental tests and consequences for herbivory. Oecologia (Berlin) 138:558-565.

$\rightarrow$ Bull, J. J., and W. R. Rice. 1991. Distinguishing mechanisms for the evolution of co-operation. Journal of Theoretical Biology 149:6374.

$\rightarrow$ Davidson, D. W., S. C. Cook, R. R. Snelling, and T. H. Chua. 2003. Explaining the abundance of ants in lowland tropical rainfores. canopies. Science 300:969-972.

Davidson, S. K., T. A. Koropatnick, R. Kossmehl, L. Sycuro, and M. $\rightarrow$ J. McFall-Ngai. 2004. NO means "yes" in the squid-vibrio symbiosis: nitric oxide (NO) during the initial stages of a beneficial association. Cellular Microbiology 6:1139-1151.

$\rightarrow$ Debout, G., A. Dalecky, A. Ngomi-Ngomi, and D. McKey. 2009. Dynamics of species coexistence: maintenance of a plant-ant competitive metacommunity. Oikos 118:873-884.

$\rightarrow$ Dethlefsen, L., M. McFall-Ngai, and D. A. Relman. 2007. An ecological and evolutionary perspective on human-microbe mutualism and disease. Nature 449:811-818.
Edwards, D. P., M. Hassall, W. J. Sutherland, and D. W. Yu. 2006. Selection for protection in an ant-plant mutualism: host sanctions, host modularity, and the principal-agent game. Proceedings of the Royal Society B: Biological Sciences 273:595-602.

Edwards, D. P., R. Arauco, M. Hassall, W. J. Sutherland, K. Chamberlain, L. J. Wadhams, and D. W. Yu. 2007. Protection in an antplant mutualism: an adaptation or a sensory trap? Animal Behaviour 74:377-385.

Eswarappa, S., G. Karnam, A. Nagarajan, S. Chakraborty, and D. Chakravortty. 2009. lac repressor is an antivirulence factor of Salmonella enterica: its role in the evolution of virulence in Salmonella. PLoS ONE 4:e5789.

Folgarait, P. J., and D. W. Davidson. 1994. Antiherbivore defenses of myrmecophytic Cecropia under different light regimes. Oikos 71: 305-320.

$\rightarrow$ Frederickson, M. E. 2005. Ant species confer different partner benefits on two Neotropical myrmecophytes. Oecologia (Berlin) 143:387395.

$\rightarrow$ Frederickson, M. E., and D. M. Gordon. 2009. The intertwined population biology of two Amazonian myrmecophytes and their symbiotic ants. Ecology 90:1595-1607.

$\rightarrow$ Gibson, C. M., and M. S. Hunter. 2010. Extraordinarily widespread and fantastically complex: comparative biology of endosymbiotic bacterial and fungal mutualists of insects. Ecology Letters 13:223234.

$\rightarrow$ Glyan'ko, A., and G. Vasil'eva. 2010. Reactive oxygen and nitrogen species in legume-rhizobial symbiosis: a review. Applied Biochemistry and Microbiology 46:15-22.

Grafen, A. 1990. Biological signals as handicaps. Journal of Theoretical Biology 144:517-546.

$\rightarrow$ Hammerstein, P., and E. H. Hagen. 2005. The second wave of evolutionary economics in biology. Trends in Ecology \& Evolution 20:604-609.

$\rightarrow$ Heath, K. D., and P. Tiffin. 2009. Stabilizing mechanisms in a legumeRhizobium mutualism. Evolution 63:652-662.

$\rightarrow$ Heil, M., and D. McKey. 2003. Protective ant-plant interactions as model systems in ecological and evolutionary research. Annual Reviews of Ecology, Evolution, and Systematics 34:425-453.

$\rightarrow$ Heil, M., M. González-Teuber, L. Clement, S. Kautz, M. Verhaagh, and J. Silva-Bueno. 2009. Divergent investment strategies of Acacia myrmecophytes and the coexistence of mutualists and exploiters. Proceedings of the National Academy of Sciences of the USA 106: 18091-18096.

Lee, K. H., and E. G. Ruby. 1994. Effect of the squid host on the abundance and distribution of symbiotic Vibrio fischeri in nature. Applied and Environmental Microbiology 60:1565-1571.

Maynard Smith, J., and D. Harper. 2003. Animal signals. Oxford University Press, Oxford.

$\rightarrow$ McFall-Ngai, M. 2008. Hawaiian bobtail squid. Current Biology 18: R1043-R1044.

$\rightarrow$ Møller, A. P. 1995. Bumblebee preference for symmetrical flowers. Proceedings of the National Academy of Sciences of the USA 92: 2288-2292.

$\rightarrow$ Mueller, U. G., J. Poulin, and R. M. M. Adams. 2004. Symbiont choice in a fungus-growing ant (Attini, Formicidae). Behavioral Ecology 15:357-364.

$\rightarrow$ Nyholm, S. V., and M. J. McFall-Ngai. 2003. Dominance of Vibrio fischeri in secreted mucus outside the light organ of Euprymna scolopes: the first site of symbiont specificity. Applied and Environmental Microbiology 69:3932-3937. 
$\rightarrow$ - 2004. The winnowing: establishing the squid-vibrio symbiosis. Nature Reviews Microbiology 2:632-642.

$\rightarrow$ Nyholm, S. V., J. Stewart, E. Ruby, and M. J. McFall-Ngai. 2009 Recognition between symbiotic Vibrio fischeri and the haemocytes of Euprymna scolopes. Environmental Microbiology 11:483-493.

$\rightarrow$ Oldroyd, G., and J. Downie. 2008. Coordinating nodule morphogenesis with rhizobial infection in legumes. Annual Review of Plant Biology 59:519-546.

$\rightarrow$ Poulsen, M., A. N. M. Bot, and J. J. Boomsma. 2003. The effect of metapleural gland secretion on the growth of a mutualistic bacterium on the cuticle of leaf-cutting ants. Naturwissenschaften 90: 406-409.

$\rightarrow$ Risch, S. J., and F. R. Rickson. 1981. Mutualism in which ants must be present before plants produce food bodies. Nature 291:149 150.

$\rightarrow$ Rothschild, M., and J. E. Stiglitz. 1976. Equilibrium in competitive insurance markets: an essay on the economics of imperfect in formation. Quarterly Journal of Economics 90:626-649.

$\rightarrow$ Ruby, E. G., and M. J. McFall-Ngai. 1999. Oxygen-utilizing reactions and symbiotic colonization of the squid light organ by Vibrio fischeri. Trends in Microbiology 7:414-420.

$\rightarrow$ Ruby, E. G., B. Henderson, and M. McFall-Ngai. 2004. We get by with a little help from our (little) friends. Science 303:1305-1307.

$\rightarrow$ Sachs, J. L., U. G. Mueller, T. P. Wilcox, and J. J. Bull. 2004. The evolution of cooperation. Quarterly Review of Biology 79:135160.

$\rightarrow$ Schaefer, H., V. Schaefer, and D. J. Levey. 2004. How plant-animal interactions signal new insights in communication. Trends in Ecology \& Evolution 19:577-584.

$\rightarrow$ Schmidt, H., and M. Hensel. 2004. Pathogenicity islands in bacterial pathogenesis. Clinical Microbiology Reviews 17:14-56.

Searcy, W. A., and S. Nowicki. 2005. The evolution of animal communication. Princeton University Press, Princeton, NJ.

$\rightarrow$ Selva, L., D. Viana, G. Regev-Yochay, K. Trzcinski, J. M. Corpa, I. Lasa, R. P. Novick, and J. R. Penadés. 2009. Killing niche competitors by remote-control bacteriophage induction. Proceedings of the National Academy of Sciences of the USA 106:1234-1238.

Simon, C. P., and L. Blume. 1994. Mathematics for economists. Norton, New York.

$\rightarrow$ Small, A. L., and M. J. McFall-Ngai. 1999. Halide peroxidase in tissues that interact with bacteria in the host squid Euprymna scolopes. Cellular Biochemistry 72:445-457.

$\rightarrow$ Soto, M. J., A. Dominguez-Ferreras, D. Perez-Mendoza, J. Sanjuan, and J. Olivares. 2009. Mutualism versus pathogenesis: the give- and-take in plant-bacteria interactions. Cellular Microbiology 11: 381-388.

Spence, M. 1973. Job market signaling. Quarterly Journal of Economics 87:355-374.

Stiglitz, J. 1977. Monopoly, non-linear pricing and imperfect information: the insurance market. Review of Economic Studies 44: 407-430.

$\rightarrow$ Sui, S., A. Fedynak, W. Hsiao, M. Langille, and F. Brinkman. 2009. The association of virulence factors with genomic islands. PLoS ONE 4:e8094.

Thompson, J. N. 1982. Interaction and coevolution. Wiley, New York.

$\rightarrow$ Tillberg, C. V. 2004. Cordia gerascanthus (Boraginaceae) produces stem domatia. Journal of Tropical Ecology 20:355-357.

$\rightarrow$ Visick, K. L., and M. J. McFall-Ngai. 2000. An exclusive contract: specificity in the Vibrio fischeri-Euprymna scolopes partnership. Journal of Bacteriology 182:1779-1787.

$\rightarrow$ Visick, K. L., J. Foster, J. Doino, M. McFall-Ngai, and E. G. Ruby. 2000. Vibrio fischeri lux genes play an important role in colonization and development of the host light organ. Journal of Bacteriology 182:4578-4586.

$\rightarrow$ West, S. A., E. T. Kiers, I. Pen, and R. F. Denison. 2002a. Sanctions and mutualism stability: when should less beneficial mutualists be tolerated? Journal of Evolutionary Biology 15:830-837.

$\rightarrow$ West, S. A., E. T. Kiers, E. L. Simms, and R. F. Denison. $2002 b$. Sanctions and mutualism stability: why do rhizobia fix nitrogen? Proceedings of the Royal Society B: Biological Sciences 269:685694.

$\rightarrow$ Weyl, E. G., M. E. Fredrickson, D. W. Yu, and N. E. Pierce. 2010. Economic contract theory tests models of mutualism. Proceedings of the National Academy of Sciences of the USA 107:15712-15716.

$\rightarrow$ Yu, D. W. 2001. Parasites of mutualisms. Biological Journal of the Linnean Society 72:529-546.

$\rightarrow$ Yu, D. W., and D. W. Davidson. 1997. Experimental studies of speciesspecificity in Cecropia-ant relationships. Ecological Monographs 67:273-294.

Yu, D. W., H. B. Wilson, and N. E. Pierce. 2001. An empirical model of species coexistence in a spatially structured environment. Ecology 82:1761-1771.

Zivkovic, A., J. B. German, C. B. Lebrilla, and D. A. Mills. 2010. Human milk glycobiome and its impact on the infant gastrointestinal microbiota. Proceedings of the National Academy of Sciences of the USA (forthcoming), doi:10.1073/pnas/1000083107.

Associate Editor: Franz J. Weissing Editor: Mark A. McPeek 